\title{
Coding patterns used by ophthalmologists for hydroxychloroquine retinal toxicity
}

This article was published in the following Dove Press journal: Clinical Ophthalmology

\author{
Stephan Y Chiu' \\ Jeremy W Shaw' \\ Tiffany Q Luong ${ }^{2}$ \\ Donald S Fong ${ }^{1-3}$ \\ Bobeck S Modjtahedi ${ }^{1,3}$ \\ 'Eye Monitoring Center, Kaiser \\ Permanente Southern California, \\ Baldwin Park, CA, USA; ${ }^{2}$ Department \\ of Research and Evaluation, Southern \\ California Permanente Medical Group, \\ Pasadena, CA, USA; ${ }^{3}$ Department of \\ Ophthalmology, Southern California \\ Permanente Medical Group, Baldwin \\ Park, CA, USA
}

Purpose: The aim of this study was to characterize International Classification of Diseases (ICD-9) coding patterns used by ophthalmologists in clinical practice for hydroxychloroquine (HCQ) retinal toxicity.

Design: This is a retrospective cohort study.

Subjects: Patients enrolled in the Kaiser Permanente Southern California health plan who were dispensed HCQ between 2001 and 2014 were included in this study.

Methods: Patients' medical records were electronically searched for the following ICD-9 codes that can be used to characterize retinopathy or maculopathy: toxic maculopathy, non-exudative age-related macular degeneration (AMD), drusen (degenerative), and/or (other) background retinopathy. The charts of patients with these codes were then manually reviewed to determine which of these patients had been diagnosed by their ophthalmologists with HCQ retinopathy.

Main outcome measures: ICD-9 codes used to indicate HCQ toxicity.

Results: A total of 23,362 patients were dispensed HCQ between 2001 and 2014. Of whom, 678 $(2.9 \%)$ patients received at least one of the aforementioned ICD-9 codes with 53 having confirmed HCQ toxicity on chart review. Forty-three patients who were taking HCQ received a diagnosis code for toxic maculopathy, and of whom, 35 (81.4\%) had HCQ toxicity. Of the patients with confirmed HCQ toxicity, $32.1 \%$ received a code other than toxic maculopathy to connote the presence of disease.

Conclusion: Although toxic maculopathy is the most commonly used ICD-9 code to identify patients with HCQ toxicity, a significant number of patients with toxicity received other codes in their medical records. Additionally, almost one-fifth of the patients who were coded as having toxic maculopathy were ultimately not diagnosed with HCQ toxicity. This study underscores the often imprecise nature of ICD coding, especially in conditions without a specific associated code. The limitations of using coding information should also be considered when conducting research that utilizes electronic databases. Future investigations should determine how to improve database searches and methods to create more uniform coding standards among ophthalmologists, especially for rare conditions such as HCQ toxicity.

Keywords: hydroxychloroquine, billing, database, plaquenil, coding, International Classification of Diseases, retinopathy, accuracy

\section{Introduction}

Hydroxychloroquine (HCQ) is used as a first-line medication in the treatment of various autoimmune conditions. Despite its established systemic efficacy, prolonged HCQ exposure use carries the risk of vision loss due to retinal toxicity. ${ }^{1} \mathrm{HCQ}$ accumulates in the retinal pigment epithelium of the macula, leading to photoreceptor damage and eventually the classic "bull's eye" maculopathy in very advanced disease. Early detection of HCQ toxicity is critical to preventing vision loss. Optical coherence tomography (OCT), multifocal electroretinogram (mfERG), Humphrey visual field 10-2, and/
Correspondence: Bobeck S Modjtahedi Eye Monitoring Center, Kaiser Permanente Southern California, Baldwin Park Boulevard, Baldwin Park, CA 91706, USA Email bobmodj@gmail.com (c) (1) (5) 2018 Chiu et al. This work is published and licensed by Dove Medical Press Limited. The full terms of this license are available at https://www.dovepress.com/terms.php (c) $\mathrm{BY}$ and incorporate the Creative Commons Attribution - Non Commercial (unported, v3.0) License (http://creativecommons.org/licenses/by-nd/3.0/). By accessing the work you hereby accept the Terms. Non-commercial uses of the work are permitted without any further permission from Dove Medical Press Limited, provided the work is properly attributed. For permission for commercial use of this work, please see paragraphs 4.2 and 5 of our Terms (https://www.dovepress.com/terms.php). 
or autofluorescence are employed by ophthalmologists for screening. ${ }^{2}$ Current guidelines recommend that patients should undergo a baseline ophthalmological examination upon starting HCQ, with annual examinations beginning 5 years after the initiation of therapy in non-high-risk individuals. ${ }^{3}$

The International classification of diseases (ICD) coding system is the standard method to document diagnoses for charting and billing purposes in the United States. The ninth vision of the system (ICD-9) was in use until the transition to ICD-10 in October 1, 2015. Searching patient records for ICD codes is a commonly employed method for health care organizations and physician groups to evaluate clinical outcomes, trends, or overall disease burden. Additionally, ICD codes are often used in research to help identify patients with diagnoses of interest, which is especially helpful when examining large cohorts of patients; however, an innate limitation of relying on ICD codes is that clinical coding patterns are often not uniform, especially for conditions without a specifically designated code. Understanding physician coding patterns and the limitations of current coding guidelines is important as ophthalmic research increasingly uses electronic databases to conduct large-scale studies. Improving our understanding of coding practices and finding areas for possible improvement are important for fully utilizing the strength of these large databases.

Within ICD coding, there is no specific code for the diagnosis of HCQ retinal toxicity. The rarity of this condition necessitates examining large cohorts of patients for retrospective studies to identify cases of toxicity. Therefore, manual review of all HCQ users is impractical. As such, ICD codes are an important tool to help guide the search for cases of HCQ toxicity. Anecdotally, the most commonly used ICD-9 code for HCQ toxicity is toxic maculopathy (362.55). Some physicians have been noted to use background retinopathy (unspecified) (362.10), although this is typically reserved for retinal vascular disease. Some physicians may also make errors in their coding or use other maculopathy codes because they are unaware of the toxic maculopathy code. It has been anecdotally observed that HCQ toxicity has been incorrectly categorized in coding records by physicians who used the code for drusen and non-exudative age-related macular degeneration (AMD) even though they had diagnosed the patient with HCQ clinically. Therefore, the purpose of this study is to evaluate ICD coding patterns for HCQ toxicity in an electronic health database.

\section{Methods}

This retrospective cohort study took place in Kaiser Permanente Southern California (KPSC). Patients who received
HCQ between 2001 and 2014 were analyzed. These patients were identified using KPSC's pharmacy database that tracks dispensed medications. The electronic medical records of these patients were then searched for ICD-9 codes for toxic maculopathy (362.55) as well as background retinopathy (362.1), non-exudative AMD (362.51), and drusen (degenerative) (362.57). The codes other than for toxic maculopathy were selected to account for atypical or erroneous coding by physicians. The charts of patients who received any of these four codes were then manually reviewed by two retina specialists to identify who had been diagnosed with HCQ toxicity by their clinicians.

This study was approved by the institutional review board of KPSC. All clinicians in our system use electronic medical records (Epic Systems, Verona, WI, USA) for both clinical charting and billing/coding. The study was compliant with the Health Insurance Portability and Accountability Act (HIPPA) and Declaration of Helsinki.

\section{Results}

A total of 23,362 patients were identified as having received HCQ during the study period. Of these, 678 received at least one ICD-9 code for toxic maculopathy, background retinopathy, drusen, and/or non-exudative AMD. Upon manual chart review, 53 of these patients were identified as having been diagnosed with HCQ toxicity by a physician.

Four hundred and thirty patients $(63.42 \%)$ received a code for non-exudative AMD, 149 (21.98\%) received a code for drusen, $116(17.11 \%)$ received a code for background retinopathy, and $44(6.49 \%)$ received a code for toxic maculopathy (Table 1). Fifty-nine patients $(8.70 \%)$ had more than one code assigned to them. Thirty-six of the 44 patients who received an ICD-9 code for toxic maculopathy were diagnosed by their treating physician with HCQ maculopathy on chart review (81.8\%). Eighty percentage of the patients with toxic maculopathy as their only code had confirmed HCQ toxicity. Meanwhile, HCQ toxicity was diagnosed in 5\% of the patients who only received a code for background retinopathy, $0.99 \%$ of the patients who only received a code for drusen, and $1.83 \%$ of the patients who only received a code for non-exudative AMD as their exclusive codes. Of patients without an ICD-9 code for toxic maculopathy, 97.31\% did not have HCQ toxicity (Table 2).

Of the 53 patients diagnosed with HCQ toxicity, 36 received at least one code for toxic maculopathy in their charts $(67.9 \%)$ and $28(52.8 \%)$ received only this code (Table 3$)$. Ten patients with confirmed HCQ toxicity $(18.87 \%)$ had at least one code for background retinopathy, and five (9.43\%) had it as their only diagnosis. Thirteen patients $(24.53 \%)$ with 
Table I ICD-9 codes used in patients using hydroxychloroquine $(n=678)$

\begin{tabular}{|c|c|c|c|c|c|c|}
\hline & $\begin{array}{l}\text { No. of } \\
\text { patients } \\
\text { with this } \\
\text { code }\end{array}$ & $\begin{array}{l}\% \text { with } \\
\text { code with } \\
\text { confirmed } \\
\text { toxicity }(\mathrm{n})\end{array}$ & $\begin{array}{l}\text { No. of } \\
\text { patients } \\
\text { with only } \\
\text { this code }\end{array}$ & $\begin{array}{l}\% \text { with only } \\
\text { this code with } \\
\text { confirmed } \\
\text { toxicity }(\mathrm{n})\end{array}$ & $\begin{array}{l}\text { \% without } \\
\text { code without } \\
\text { confirmed } \\
\text { toxicity }\end{array}$ & $\begin{array}{l}\text { Additional codes } \\
\text { used in patients with } \\
\text { confirmed toxicity }\end{array}$ \\
\hline $\begin{array}{l}\text { Toxic } \\
\text { maculopathy }\end{array}$ & 44 & $81.82(36)$ & 35 & $80(28)$ & 97.48 & $\begin{array}{l}\text { Drusen (3), AMD (3), and } \\
\text { background retinopathy (3) }\end{array}$ \\
\hline $\begin{array}{l}\text { Background } \\
\text { retinopathy }\end{array}$ & 116 & $8.62(10)$ & 101 & $4.95(5)$ & 92.35 & $\begin{array}{l}\text { Drusen (I), AMD (I), and } \\
\text { toxic Maculopathy (3) }\end{array}$ \\
\hline $\begin{array}{l}\text { Drusen } \\
\text { (degenerative) }\end{array}$ & 149 & 4.70 (7) & 101 & $0.99(I)$ & 91.30 & $\begin{array}{l}\text { AMD (3), Toxic } \\
\text { maculopathy (3), and } \\
\text { background retinopathy (I) }\end{array}$ \\
\hline $\begin{array}{l}\text { Non-exudative } \\
\text { AMD }\end{array}$ & 430 & $3.02(13)$ & 382 & I.83 (7) & 83.87 & $\begin{array}{l}\text { Toxic maculopathy (3), } \\
\text { background retinopathy } \\
\text { (I), and drusen (3) }\end{array}$ \\
\hline
\end{tabular}

Abbreviation: AMD, age-related macular degeneration.

HCQ toxicity had received an ICD-9 code for non-exudative AMD, and seven (13.21\%) had it as their only diagnosis. Seven patients with HCQ toxicity (13.21\%) had an ICD-9 code for drusen (degenerative), and one (1.89\%) had it as their only diagnosis.

\section{Discussion}

The purpose of this study was to examine practice patterns for ICD coding of HCQ toxicity in a large and real-world population of patients and physicians. Databases are increasingly being utilized to study important clinical questions. A better understanding how ophthalmologists are coding for eye diseases, and possible ways to improve their accuracy, will be important to maximizing the utilization of these databases going forward.

Although toxic maculopathy was the most commonly used ICD code for HCQ toxicity, this study demonstrates that using this code exclusively to identify patients with HCQ toxicity is problematic. $18.2 \%$ of the patients who carried this ICD code were not actually diagnosed with HCQ toxicity by their physicians. In practice, this code may be used by physicians referring patients to retina specialists, with subsequent follow-up evaluation failing to demonstrate true toxicity; however, the patient will still be identified as having had this code associated with them at some point in

Table 2 Sensitivity, specificity, PPV, and NPV for ICD-9 codes for toxic maculopathy for identifying patients with hydroxychloroquine toxicity

\begin{tabular}{ll}
\hline Value & Percentage \\
\hline Sensitivity & 67.92 \\
Specificity & 98.72 \\
PPV & 81.82 \\
NPV & 97.31 \\
\hline
\end{tabular}

Abbreviations: NPV, negative predictive value; PPV, positive predictive value. their care during a database search. Alternatively, the patient could have toxic maculopathy secondary to medications other than HCQ, although this is likely less common.

Although toxic maculopathy is the most commonly used code by ophthalmologists to connote HCQ toxicity in patients' charts, the use of other codes was not infrequent. Patients who did not have a code for toxic maculopathy in their chart were very unlikely to have HCQ toxicity, which is not surprising as this is a rare condition that is unlikely to be diagnosed in general. Conversely, among patients with confirmed toxicity, $32.1 \%$ had not received a code of toxic maculopathy at any point in their care, and instead received codes for conditions such as AMD and drusen. This indicates a relatively low sensitivity for identifying true cases of HCQ toxicity based on the code for toxic maculopathy. This may be because of physician unfamiliarity with the toxic maculopathy ICD-9 code, initial misdiagnosis that was not corrected on subsequent coding, or simple physician error in entering codes into the computer; however, these findings demonstrate that toxic maculopathy cannot be reliably used as the sole code for identifying patients with HCQ toxicity.

It is more difficult to identify patients with HCQ toxicity through ICD-9 searches than for other, more common diseases such as cataracts and diabetic retinopathy. Diabetic retinopathy and cataracts have been found to be coded with good accuracy, which may be because clinicians are familiar with the full scope of these codes due to their frequent use. ${ }^{4,5}$ Additionally, these codes are very granular, allowing maximal accuracy and specificity when selecting the correct diagnosis. Finally, codes for cataracts and diabetic retinopathy are often linked to surgical or office procedures with subsequent conditional reimbursement, further incentivizing the need for accurate coding. In contrast, the most recent ICD classification, ICD-10, still does not include a specific 
Table 3 Patients with hydroxychloroquine toxicity and their associated ICD-9 code(s), ${ }^{a} n=53$

\begin{tabular}{llllll}
\hline & $\begin{array}{l}\text { Toxic } \\
\text { maculopathy } \\
\%(\mathbf{n})\end{array}$ & $\begin{array}{l}\text { Background } \\
\text { retinopathy } \\
\%(\mathbf{n})\end{array}$ & $\begin{array}{l}\text { Drusen } \\
\text { (degenerative) } \\
\%(\mathbf{n})\end{array}$ & $\begin{array}{l}\text { Non-exudative } \\
\text { AMD \% (n) }\end{array}$ & $\begin{array}{l}\text { Total } \\
\%(\mathbf{n})\end{array}$ \\
\hline Toxic maculopathy & $52.8(28)$ & $5.66(3)$ & $3.77(2)$ & $3.77(2)$ & $67.9(36)$ \\
Background retinopathy & $5.66(3)$ & $9.43(5)$ & $1.89(1)$ & $1.89(1)$ & $18.9(10)$ \\
Drusen (degenerative) & $3.77(2)$ & $1.89(1)$ & $1.89(1)$ & $3.77(2)$ & $13.2(7)$ \\
Non-exudative AMD & $3.77(2)$ & $1.89(1)$ & $3.77(2)$ & $13.2(7)$ & $24.5(13)$ \\
\hline
\end{tabular}

Notes: ${ }^{5} 52.8 \%$ of the patients had only an ICD-9 code for toxic maculopathy, $5.66 \%$ of the patients carried a code for both toxic maculopathy and background retinopathy, $3.77 \%$ of the patients had a code for toxic maculopathy and drusen, etc. 'ln addition, one patient (I.89\%) had three diagnoses: non-exudative AMD, toxic maculopathy, and drusen (degenerative).

Abbreviation: AMD, age-related macular degeneration.

code for HCQ retinal toxicity. This likely contributes to the inaccuracy of coding seen in this study.

There are several limitations to this study. All the patients belonged to one medical group (Kaiser Permanente Southern California), which could lead to the lack of generalizability; however, there are over 100 ophthalmologists within this system who have diverse training backgrounds. In addition, some cases of HCQ toxicity may have been missed from our search if other, more rarely or incorrectly used, codes had been utilized by some physicians. It is important to note that the purpose of this study was not to assess the accuracy of HCQ toxicity diagnoses but rather to determine the coding patterns used by physicians who felt that their patients had this condition. The strengths of this study are its large diverse population of HCQ users and the relatively large number of HCQ toxicity cases examined.

\section{Conclusion}

A significant number of patients who carry the ICD code for toxic maculopathy did not have HCQ toxicity on chart review, and approximately one-third of the patients with confirmed HCQ toxicity were not assigned a code for toxic maculopathy. Clinicians often use other, technically incorrect, codes for patients with HCQ toxicity. Identifying patients with HCQ toxicity, as well as other less common disorders without specific ICD codes, in database searches is inaccurate without casting a large net with multiple related codes and relying on confirmatory chart review. Efforts should be made to improve the accuracy of database searches in the future without needing to rely so heavily on the labor intensive nature of manual chart review. Natural language processing may hold promise in this area. Although this HCQ toxicity is rare, it is an important cause of preventable visual morbidity and an area of considerable research that relies on extensive database searches. As a result, an effort should be made to create more granular ICD codes within ophthalmology, specifically for HCQ toxicity, in the future. In the meantime, the ophthalmic community should work toward standardizing the approach for coding rare conditions and better educate ophthalmologists as well as optometrists to create and follow more uniform clinical coding practices.

\section{Acknowledgment}

This study was presented at The Association for Research in Vision and Ophthalmology Annual Meeting, Honolulu, Hawaii, 2018.

\section{Disclosure}

DS Fong has the following disclosure outside of the submitted manuscript: grants from Allergan, ThromboGenics, and Nightstar. The authors report no other conflicts of interest in this work.

\section{References}

1. Elman A, Gullberg R, Nilsson E, Rendahl I, Wachtmeister L. Chloroquine retinopathy in patients with rheumatoid arthritis. Scand J Rheumatol. 1976;5(3):161-166.

2. Marmor MF. Comparison of screening procedures in hydroxychloroquine toxicity. Arch Ophthalmol. 2012;130(4):461-469.

3. Marmor MF, Kellner U, Lai TYY, Melles RB, Mieler WF; American Academy of Ophthalmology. Recommendations on Screening for Chloroquine and Hydroxychloroquine Retinopathy (2016 Revision). Ophthalmology. 2016;123(6):1386-1394.

4. Muir KW, Gupta C, Gill P, Stein JD. Accuracy of international classification of diseases, ninth revision, clinical modification billing codes for common ophthalmic conditions. JAMA Ophthalmol. 2013;131(1): 119-120.

5. Lau M, Prenner JL, Brucker AJ, Vanderbeek BL. Accuracy of Billing Codes Used in the Therapeutic Care of Diabetic Retinopathy. JAMA Ophthalmol. 2017;135(7):791-794. 
Clinical Ophthalmology

\section{Publish your work in this journal}

Clinical Ophthalmology is an international, peer-reviewed journal covering all subspecialties within ophthalmology. Key topics include: Optometry; Visual science; Pharmacology and drug therapy in eye diseases; Basic Sciences; Primary and Secondary eye care; Patien Safety and Quality of Care Improvements. This journal is indexed on

Submit your manuscript here: http://www.dovepress.com/clinical-ophthalmology-journal

PubMed Central and CAS, and is the official journal of The Society of Clinical Ophthalmology (SCO). The manuscript management system is completely online and includes a very quick and fair peer-review system, which is all easy to use. Visit http://www.dovepress.com/ testimonials.php to read real quotes from published authors. 